\title{
Estruturas e modelos de ensino excludentes no Brasil: revisitando a história da formação e identidade profissional da Enfermagem
}

Excludent structures and models of education in Brazil: revisiting the history of Nursing education and professional identity

CAMPOS, Paulo Fernando de Souza; OGUISSO, Taka.

Enfermagem no Brasil: formação e identidade profissional pós-1930. 1. ed. São Caetano do Sul: Yendis, 2013. v. 1. 211 p.

Os debates políticos construídos acerca de demandas que envolvem os temas das dinâmicas das relaçóes raciais no Brasil e educação, têm consentido, ainda que minimamente, inclusão de seus conteúdos nos estudos e pesquisas em diferentes áreas de conhecimento. O livro em exposiçáo, resultado do estudo desenvolvido por Paulo Fernando de Souza Campos em sua pesquisa de pósdoutorado em História da Enfermagem, pelo Programa de Pós-Graduação da Universidade de São Paulo (USP), no período de julho de 2006 a junho de 2009, sob orientação de Taka Oguisso, renomada enfermeira e pesquisadora sobre história e legislação na enfermagem, caracteriza bem essas novas tendências teóricas, metodológicas e conceituais, ainda que timidamente, presentes nos circuitos científicos educacionais.

1 Enfermeiro, Mestre em Educação, Discente do Doutorado em Educação pelo Programa de Pós-Graduação em Educação -PPGE, da Universidade Federal de Mato Grosso -UFMT, vinculado ao Núcleo de Estudos e Pesquisas sobre Relaçóes Raciais e Educação -NEPRE, Servidor, Técnico Administrativo em Educação da UFMT. E-mail: <valdeciconexoes@gmail.com>.

2 Coordenadora e pesquisadora do Núcleo de Estudos e Pesquisas sobre Relações Raciais e Educação -NEPRE e professora do Programa de Pós-Graduação em Educação da Universidade Federal de Mato Grosso PPGE/ UFMT, nível Mestrado e Doutorado. Ministra desde o ano de 2012, a Disciplina optativa, "Educação para as Relaçóes Étnico-Raciais” no Curso de Enfermagem da Faculdade de Enfermagem - FAEN da UFMT. E-mail:<candidasoarescosta@gmail.com>.

\begin{tabular}{|c|c|c|c|c|c|}
\hline R. Educ. Públ. & Cuiabá & v. 27 & n. 66 & p. 1021-1025 & set./dez. 2018 \\
\hline
\end{tabular}


Campos e Oguisso (2013) lançam, com esse livro, novas narrativas e perspectivas de pesquisas educacionais no campo de estudo da história da profissionalização da enfermagem no Brasil. Nesse movimento, revelam atores sociais negros que também contribuíram para a construção da identidade profissional da enfermagem, embora sistematicamente esquecidos por diversas formas e meios, inclusive pelos espaços institucionais formativos. Por motivaçóes raciais, compreendiam que mulheres negras não constituíam a imagem da enfermeira idealizada e nem como membros que formariam a naçáa brasileira.

$\mathrm{O}$ racismo ostentado, estruturado, institucionalizado e disseminado tornara-se uma arma ideológica importante na elaborada identidade profissional da enfermagem. Tese essa que é defendida pelos autores já na parte inicial do livro, com desdobramento em todo o corpo do texto a partir de minuciosas e criteriosas análises. $\mathrm{Na}$ apresentaçáo, os autores se reservam a localizar o leitor sobre a origem de suas fontes de estudo para produção da pesquisa, bem como a escolha do método utilizado. Situam, também, como o modelo de ensino preconizado à profissionalização da enfermagem a partir de 1920, no Brasil, impediu o acesso de mulheres negras e homens à Escola de Enfermagem. Argumentam sobre a existência de significativa alteração desse processo com a fundação da Escola de Enfermagem em São Paulo, em 1942.

No capítulo um, intitulado Cosmopolitismo estigmatizado: debate racial e a enfermagem no Brasil República, os autores abrem discussão sobre relaçôes raciais no país e na enfermagem. Ao abordarem o Racismo e enfermagem brasileira, dialogam com Ieda de Alencar Barreira (1997), Luís Antônio de Castro Santo e Lina Faria (2004) e outros historiadores do campo da profissionalização da enfermagem. Nesse diálogo, Campos e Oguisso (2013) retratam que a implantação oficial do Modelo Nursing cristalizou a profissão como própria para mulheres brancas, pois na organização institucional, excluíam candidatas negras.

Assim, a construção da identidade profissional da enfermagem foi sendo forjada com base em conhecimentos eugênicos, que já compunham a teia social, privilegiando grupos e estigmatizando outros como impróprios à nação e à profissão em enfermagem. Nessa contextualização, contrapondo a história oficial, os autores destinam atenção para o tópico seguinte, Cuidadoras negras: a história (não contada) da enfermagem brasileira. Para ambos, as amas de leite negras foram uma das primeiras práticas do cuidado formalmente executadas no Brasil, contudo, a matriz teórica da medicina eugênica foi decisiva para seu banimento, principalmente com a instauração do regime político republicano.

No segundo capítulo, denominado Modernidade e Americanizaçâo: Serviço Especial de Saúde Pública (Sesp), os autores centram atenção no processo de americanização da América Latina. Para representar esses episódios transplantados às áreas de conhecimento em saúde e da enfermagem, os autores 
elegem a figura emblemática de Nelson Aldrich Rockefeller, segundo filho de John D. Rockefeller Jr., da família multimilionária, donos da Standard Oil Company, empresa presente em vários países da América Latina. Essa empresa, ao corroborar financeiramente com a implantação da profissionalização da área de saúde e da enfermagem no país, contribuiu também para sua caracterização política e identitária.

Em Programa de enfermagem: enfermeiros para o Brasil, Campos e Oguisso (2013) mostram, como a Escola de Enfermagem de São Paulo estava moldada ao populismo assumido por Getúlio Vargas (1930-1945). Ao caracterizarem esse movimento político, os autores afirmam que, "[...] ao exaltar qualidades como ordem e disciplina, a enfermagem encontrava ressonância com as ideias populistas, valores que as candidatas à alunas na Escola de Enfermagem de São Paulo, registravam com significativa proximidade.” (CAMPOS; OGUISSO, 2013, p. 34).

Assim, em Identidade profissional: a (nova) enfermagem brasileira, Campos e Oguisso (2013, p.71) sáo contundentes em afirmar que "[...] o ensino proposto pela Escola de Enfermagem de São Paulo imprimia novas representaçóes à identidade profissional." Ao fazerem tal afirmação, apresentam várias informaçóes que compunha a formação nessa escola. Com toda uma nova logística profissional, representando o contexto empreendedor da época, os autores afirmam que, "[...] estudar no maior Centro Hospitalar da América Latina fabricava representaçóes e sociabilidades que projetavam suas alunas como modernas e profissionais" (CAMPOS; OGUISSO, 2013, p. 71). Nessas análises, os autores abrem o debate em torno do tópico a seguir, que imprime, então, a mensagem do modelo de ensino assumido, a enfermagem de alto padrão.

Argumentam que havia em torno da admissão das alunas uma série de critérios que se alinha à busca de um novo padrão de formação e orientação profissional. Eles destacam que "[...] a experiência anterior que notabilizou o modelo-padrão de ensino e assistência, não mais respondia às demandas existentes, inclusive por desconsiderar a possibilidades de mulheres negras e homens ingressarem na escola-modelo, como apontado." (CAMPOS; OGUISSO, 2013, p. 75).

No capítulo três, nomeado Liderança Paulista: a Escola de Enfermagem de São Paulo, os autores, em linhas gerais, se dedicam a apresentar a criação da Escola de Enfermagem de São Paulo, seus objetivos e idealizaçóes daqueles que estavam à frente de sua estruturação e organização. Destacam que a Escola atribuiria nova visibilidade à formação e identidade profissional, pois ela foi de grande abrangência na formação de enfermeiras para o Brasil, inclusive "[...] reinserindo mulheres negras e homens na enfermagem nacional [...]" (CAMPOS; OGUISSO, 2013, p. 90). Destacam também que a Escola seguiu 
os princípios norte-americanos de ensino, representante do Modelo Nursing. A escola mantinha, ainda, vinculação, desde a sua criação, a uma instituição de ensino superior e a um Hospital Escola. Segundo afirmação dos autores, todos esses requisitos contemplados alinhavam a escola de enfermagem a todos os rigores acadêmicos exigidos na época.

No capítulo quatro, Enfermeiras-Sesp: A Enfermagem em Novas Dimensöes, os autores oportunizam compreender o redimensionamento no ensino da Enfermagem no país. Para eles, diferente do modelo anterior, a formação em enfermagem voltava-se às práticas preventivas e profiláticas. Nessa apresentação, situam a Escola de Enfermagem de São Paulo e sua vinculação ao Programa de Enfermagem. Para os autores, essa parceria permitia novos avanços tecnológicos para uma formação voltada para assistência do campo da administraçáo, condição essa em concordância com o desenvolvimento econômico e social que marcou a Era Vargas.

Assim, no capítulo cinco, Ilustre Inominadas Mulheres Negras na Enfermagem Brasileira, Campos e Oguisso apresentam, por meio de fotografias, mulheres negras diplomadas em enfermagem que também contribuíram significativamente na formação da identidade profissional, ainda que invisibilizadas por não serem a imagem da enfermeira idealizada. Em suas consideraçóes finais, os autores optam em retratar como as representaçóes históricas da profissão enfermagem e a construçáo de sua identidade profissional estiveram vinculadas a um modelo de ensino excludente e discriminatório.

As questôes exploradas minuciosamente pelos autores nessa obra tendem a se tornar um marco de referencial teórico importante nos estudos e pesquisas de temas acerca da educação das relações raciais e formação em saúde e na enfermagem. Nesse movimento, abrem-se caminhos de estudos e pesquisas até entâo ignorados ou considerados sem relevância social.

O livro se destaca pela originalidade do tema abordado, sendo uma leitura indispensável a vários segmentos que compóem o campo das ciências sociais e humanas e, principalmente, das ciências de saúde e da enfermagem. Trata-se de uma leitura com significativa importância para os estudiosos e pesquisadores do campo da história da profissionalização da enfermagem e da saúde e se revela, além disso, como um conteúdo importante para reflexôes na formação nessas áreas de conhecimento. Situa-se importante também aos militantes sociais que visam contribuir para o enfrentamento das iniquidades raciais em saúde e, consequentemente, para o enfrentamento do racismo na sociedade brasileira e aos que elegem a educação como instrumento indispensável nesse processo. 


\section{Referência}

CAMPOS, Paulo Fernando de Souza; OGUISSO, Taka. Enfermagem no Brasil: formação e identidade profissional pós-1930. 1. ed. São Caetano do Sul: Yendis, 2013. v. 1. 211 p. 